\title{
TECHNOLOGY ROADMAP: LAB-ON-A-CHIP
}

Recebido em 05.12.09 / Aceito em 18.03.10

\section{Tugrul U Daim¹ e Pattharaporn Suntharasaj²}

Acknowledgements: We would like to acknowledge the work of Linda Lin, Neslihan Sener and Kayoko Mito in gathering the initial data for this project.

\begin{abstract}
With the integration of microfluidic and MEMS technologies, biochips such as the lab-on-a-chip (LOC) devices are at the brink of revolutionizing the medical disease diagnostics industries. Remarkable advancements in the biochips industry are making products resembling Star Trek's "tricorder" and handheld medical scanners a reality. Soon, doctors can screen for cancer at the molecular level without costly and cumbersome equipments, and discuss treatment plans based on immediate lab results. This paper develops a roadmap for a hypothetical company (XI) which is seeking to be successful in this market. The roadmapping process starts with gathering data through literature research and expert opinions, and progress through defining the market/product/technology layers, linking and integrating these layers, and finally creating a labon-a-chip for disease diagnostics technology roadmap.
\end{abstract}

\footnotetext{
${ }_{1}^{1}$ Portland State University, Dept. of Engineering and Technology Management. E-mail: tugrul@et,.pdx.edu

${ }^{2}$ Portland State University, Dept. of Engineering and Technology Management. E-mail: patt.suntharasaj@gmail.com
} 


\section{Background}

For several decades, the microelectronics industry has sustained tremendous growth and has become what is arguably the most dominant and influential industry for our society. This industry has undoubtedly touched almost every aspect of our modern lives from personal computers to medical imaging devices. But, with the electronic industry facing new and significant challenges as component device feature sizes shrink into the nanometer scale, one cannot help but wonder what is next? What will this new paradigm bring?

As the microelectronics technology matures, other disruptive technologies such as the MEMS and microfluidics emerge and are currently gaining momentum. This is not to say that these new technologies will eventually replace the microelectronics technology however they will and has already begun to open up a whole new world of innovations and technological advances, especially in the biotechnology sector. Innovations such as array biochips and microfluidic-based biochips (lab-on-a-chip) devices are becoming a commercial reality; these biochips are transitioning out of the academic and pharmaceutical research realm to more commercialized applications for routine analysis such as medical diagnostics, environment and agri-business, and pathogen detection [1]. Soon, mothers can routinely test their children at home for flu. Doctors can screen patients for cancer and begin discussing treatment based on the immediate results. Farmers can scrutinize the health of animals, and soldiers and environmental inspectors can test for pathogens and pollutants in their environment without making timeconsuming trips to the lab.

In recent years, an incredible amount of research and development on biochips has contributed to the rapid evolution of the biotechnology industry. Biochips are defined as "microsystems with tailored surface properties for life science applications [1]." Simply put, they are devices or microchips containing organic materials. Early biochips were based on the concept of a DNA microarray designed for the purpose of accelerating genetic research. A DNA microarray is a piece of glass, plastic or silicon substrate on which pieces of DNA were affixed in a microscopic array [2]. The affixed DNA segments are probes. Scientists use these chips to screen a biological sample simultaneously for the presence of many genetic sequences at once. Now, biochips are not limited to DNA analysis. Protein biochip array, antibody biochip array and chemical compound biochip array are also available to for disease screening, diagnosis, and monitoring [3]. A drawback of these arrays is that they are neither reconfigurable nor scalable after manufacturing. Moreover, they lack the ability to carry out sample preparation, which is critical to biochemical applications [2].

Lab-on-a-chip (LOC), on the other hand, is a subset of biochips that generally refers to the scaling of single or multiple lab processes down to a chip format [4]. The basic idea of LOC or microfluidic biochips is to integrate all necessary functions for biochemical analysis onto one chip using microfluidics and MEMS technology. In general, LOCs consolidate three traditional functions (sample preparation, analytic separation, and detection) into a single, triple-purpose device. These biochips are essentially miniaturized laboratories that can perform hundreds or thousands of simultaneous biochemical reactions. Like all biochips, their substrates (made of glass, silicon, or polymer) carried probes (either DNA, proteins or tissues) that are used to identify targets (e.g. disease, pathogens, etc.) in a complex biological sample [1].

Although the application of LOC is still novel and modest, these biochips are receiving much attention nowadays. They offer a number of advantages over conventional laboratory procedures. First, they automate highly repetitive laboratory tasks by replacing cumbersome equipment with miniaturized and integrated systems. This can in turn reduce the risk in human 
errors and sample contamination through manual handling. Second, they enable the handling of small amounts (micro and nanoliters) of fluids. This means smaller sensors and chemical reaction chambers, which equates to reduced cost of testing. In addition, LOC also enable researchers to quickly screen large numbers of biological analytes for purposes that range from disease diagnosis to detection of bioterrorism agents [2], [1].

The future trend of biochips is heading toward smaller, cheaper, and faster integrated lab-on-a-chip devices. However, despite all the advances in the development of miniaturized sensing and analytical components for use in a variety of biomedical and clinical applications, the ability to assemble and interface individual components in order to achieve high level of integration in complete working systems continue to pose daunting challenges for industry as a whole [5]. In order to achieve the ideal LOC vision, the future of the biochips (LOCs) industry will depend heavily on the collaboration of multiple disciplines such as the biological, physical, chemical, and engineering sciences to bridge the gaps in technology and establish industry standards to support mass commercialization.

\section{Methodology}

As mentioned before, companies have long used technology roadmapping as a tool to help them plan strategically for the future. There is a wide range of roadmaps and roadmapping methodologies to choose from. The most common roadmap is a time-based chart, multi-layer roadmap with its layers interlinked to show the impact and interactions between the sub-elements [6]. In this project, we choose the T-Plan Fast-Start Methodology from the University of Cambridge to guide us through our roadmapping process.

The T-Plan process consists of two main parts [6]:

1. Standard approach to support product planning.

2. Customized approach to support a broad range of different business aims.

Since roadmapping supports a wide range of business aims, the standard T-Plan process described above will not fit all planning focuses. Moreover, for the reasons that each organizations has its own "particular business context, organizational culture, business processes, available resources, technology types, etc. [6]", effective roadmapping should be customized and tailored to suit its unique application. Our team finds this to be the case as well for our technology roadmapping process.

In order to achieve the desired effectiveness of roadmapping, we tailored the standard T-Plan process to fit our project. Our research methodology is a two-pronged approach: 1) Literature Research Path, and 2) Expert Delphi Path. An Expert Delphi path with its panel of five experts was used to validate the data and findings. [7].

\section{Market analysis}

Process of analyzing target market is capable of differentiating a company from its competitors by serving better products and services with premium price and values to fulfill requirements of the target customers. "A market-based business will set prices based on customer needs and the strength of its product position relative to competitors [8]". Research is intended 
to assist in predicting the direction of the market and exploring who purchases a product and a reason for the purchase directly drive the future of the company [9], [10].

Research and Market presented "the total biochip market size in 2004 is about \$2.0 billion and is forecasted to grow to about $\$ 5.1$ billion in 2009 with a CAGR of 20.2\%"[12]. Pharmaceutical companies want to become financial and research partners for biochip and biotechnology companies since actual productivity of pharmaceutical companies have been declined. Those biochip and biotechnology companies may have a capability to make pharmaceutical companies more productive by using their technologies.

According to Charles Smith of Bell Labs, the first manifestation of MEMS, that the piezoresistive effect in Germanium and Silicon, was discovered in 1954. It is been more than fifty years since MEMS research, design, and development has begun. "Many people ask, "Why has is taken so long for the MEMS/MST, Microsystems Technologies, market and technology to realize its potential or reach the expected volumes? Will Nanotechnology face the same barriers? [10]"

Roget Grace Associates introduced a "MEMS Industry Report Card." It reported that there were modest advances in marketing grades from a value of C- to C+, from 1998 to 2004 respectively. It pointed that MEMS/MST companies have not conducted formal market research in order to determine customer requirements and value of prices. In comparison to the semiconductor industry, which implemented excellent and significant marketing/promotion activities, rigorous and in-depth market research and marketing expertise are still lacking in MEMS/MST industry. "Faster, better, cheaper is the mantra of the semiconductor industry in direct response to customers' needs. MEMS/MST producers need to adopt a similar customercentric attitude. [11]"

There is a report for biosensors worldwide market as well. The market size for worldwide biosensors were estimated approximately $\$ 7.3$ billion at the end of 2003. The market is forecasted to increase about $\$ 10.8$ billion with a growth rate of approximately $10.4 \%$ in 2007 . Some representative application areas are 1) monitoring glucose levels of diabetic patients driven by the increasing ratio of obesity and the alarming rise in the ratio of diabetes in the developed countries and 2) the need for next-generation assay biosensors, which can motivate the progression of drug discovery. Applications for environmental pollution, safety for food and beverage, and military and civil defense fields have been also noticed as growing markets [12].

Well understanding our target market is highly important. In other words, a company who thoroughly researched its target market has the greatest opportunity to become the market leader in the market. In this section, we classified biochip market into smaller sub-groups and executed market profiles. The overall biochip market is classified into five major market segments; pharmaceutical R\&D, academic research, diagnostic, environment and agribusiness segments. Approximately 80 to $90 \%$ of the biochip market was dominated by pharmaceutical and academic research in 2004 [14].

Basic research involving genome mapping and sequencing laboratories and applications for drug discovery account for biochips' current demand. Drug discovery and disease discovery applications using the biochip technology in pharmaceutical research is the currently most remarkable field in Europe. Diagnostic examination and environmental monitoring are the other fields growing rapidly. "Organizations are realizing that efficiency, accuracy, and productivity improvements lie in the exploitation of biochip technology [15]."

Jain PharmaBiotech reported in 2005 that the worldwide molecular diagnostic market was worth $\$ 6.5$ billion. By 2010, the diagnostic market will grow to $\$ 12$ billion and to $\$ 35$ billion in the year of 2015. Advancements in genomics and proteomics are the primary attributions. 
Importantly, factors contributing significantly to the growth of the molecular diagnostic market are biochip and nanobiotechnology [16].

Generally, a market is motivated by its market drivers. Finding important market drivers ensures the sustainable market demands. We came up with five key market drivers influencing positively to human diagnostic market.

\section{Global Market Needs (HIV and H5N1 Avian Influenza Pandemic)}

Tackling widespread public phobia of HIV and H5N1 Avian Influenza is the strongest market drivers to human diagnostic segment. This market driver is globally remarkable and sustainable for a long time because of future viral uncertainties.

In 1997, humans were firstly infected by H5N1 strain in Hong Kong which caused eighteen cases and six deaths. "Since mid-2003, this virus has caused the most severe outbreaks in poultry on record. In December 2003, infections in people exposed to sick birds were identified [17]." Humans are not infected by the most avian influenza viruses. When a new subtype of influenza viruses emerge that humans are not immune, an influenza pandemic occurs. H5N1 avian influenza has a high importance since it might eventually adapt into a strain that is contagious among humans [17].

On the other hand, HIV is one of the most critical pandemic issues. 400,000 people have died and over one million people have been infected by AIDS/HIV just in the U.S. More than 22 million people in the world have died from this virus. The United Nations has anticipated that more than 40 million children in Africa will be orphaned by AIDS/HIV by 2010 [18].

Obviously, there are tremendously huge markets toward those pandemic issues over the world. Health practitioners are waiting for an advent of diagnostic tool which enables immediate detection of H5N1 avian influenza and other influenza viruses [19]. Worldwide non-governmental organizations (NGOs), such as UNICEF, are also directly involved in this. They are willing to have less-expensive diagnostic tools with large volumes.

\section{Health Awareness}

Particularly in the U.S., people are becoming more aware of health related issues. Obesity, cancer, and any epidemical diseases are some of the examples. Regarding obesity, it may surpass smoking as the leading cause of preventable death. While obesity used to be a problem only in developed countries, developing nations notice their overweight population is growing. As for awareness of cancer, cancer is best treated when it is detected early. By distributing the biochip upon the purpose at a less expensive price, people will be more aware of the importance of early detections. Simultaneously, this market driver is also hard to be neglected due to hidden future market potentials which will be enlarged by promotions via media. 


\section{Increasing Aging Population}

The number of population who are 65 years or older have been increased globally. The population over 65 years old was 36.3 million in the year of 2004 in the U.S. and they represented approximately $12.4 \%$ of the overall U.S. population. The administration of aging, in the department of health and human services, estimated that this population will be 71.5 million by the end of 2030 [20]. In Japan, baby boomers start becoming 60 years old in 2007 [21]. According to the annual report on the aging society 2005, the number of population aged 65 or older recorded 24.88 million [22].

\section{Cost of Health Care}

Insurance cost to cover the healthcare varies depending on a nation. Insurance systems in some countries respect seniority and older population is required to pay less than younger generation. Some of the countries in Europe and Japan can be listed in this category. However, in the U.S., older people still need to pay large amount of money when they see a doctor. They also need to pay for insurance costs. Less expensive diagnostic tools would be more affordable for those people. Xtreme Intelligent thinks the generation wants to use those tools for the purpose of early disease detection as well, which is relevant to the health awareness market driver.

\section{Miniaturized trend}

As for current technological trend, especially in biochip field, many of the technologies have become miniaturized. This natural technological movement is considered indispensable. Additionally, miniaturized features are one of the most vital advantages that biochips have. Blessed with development advancement of this trend, biochips will be distributed into not only among institutions and NGOs, but also general public in the near future.

While different companies in the same market will gain different levels of profitability, it is useful to set a guideline for knowing how severe it is to be profitable in the market by researching estimated profit potential [23]. Companies already established their positions in the biochip market are in a constant competition to either acquire new patents or validate those of their rivals. Patents are one of the barriers to enter the market [24]. The supplier selling power in the biochip market is relatively high. One reason is that switching cost is high in the industry. Since one product itself priced expensive in the market, switching from one biochip manufacture to another is costly. Vertical integration is also one reason makes the supplier power high. In other words, suppliers in the field are concentrated. Relationships among those manufactures and buyers are comparatively solid [25], [26], [27].

When quite a few alternative products are available, customers can easily switch from a company to another. Overcoming such a hurdle requires enormous amount of resources and costs. Most of the companies in the market are reluctant to take an action to launch variety of substitute products [8], [28]. The "industry demonstrates a peculiar balance between rivalry and codependence [29]." We have seen competitions in the human diagnostic biochip market. 
However, it is also true that companies need to rely on alliances with other biochip manufacturers obtaining different technologies and their capabilities. Regarding manufacturing Lab-on-a-Chip (LOC), several different technologies and those processes are integrated on one chip. Considering limited resources in a company and necessities of different technologies, there has been no example that all of the LOC manufacturing processes are accomplished by one company. Instead, companies, such as STMicroelectronics, are making alliances to be codependent to another company, laboratory, or manufacture [30]. Some of the equipments for LOC manufacturing processes are similar to that utilized in the semiconductor industry. However, customization of those equipments applicable to biochip manufacturing is mandatory and is hard to be reversed. Those barriers concern companies and hold the industry being not reaching to mature. Concurrently, there is still tremendous amount of hidden growth in the market, which could be exploded by revolutionary manufacturing method [29].

"Cost savings accomplished by eliminating and reducing the factors an industry competes on. Buyer value is lifted by raising and creating elements the industry has never offered [31]." The figure of Ansoff's growth matrix is similar to the blue ocean matrix, which is also a wellknown strategic modeling tool. The matrix is popular and one of the reliable tools to determine business growth opportunities [32]. The results give a basis for assessing the host company's intended method of growth and their interrelationship among competitors [33].

\section{Product analysis}

An increasingly ageing population puts a severe financial strain on the healthcare system. Also, the governments want to spend less money on the healthcare. Those challenges could be meet by miniaturizing, integrating, automating analysis systems and reducing the time devoted to each patient. At that point, our strategic product arises as the Lab-on-a-chip.

Point-of-care testing is a growing market and research groups are trying to combine new and established findings to construct a small handheld device that can analyze a blood sample for common biomarkers and produce results within a short time.

Lab-on-a-chip enables total automation and integration of material handling, eliminates the need for human intervention and drastically reduces the sample size requirement; all which lead to cost reduction. As we discussed in the Market Analysis, many companies are trying to get better and new products to be the market leader or stay competitive. However, there is an inevitable gap which is the sample preparation. We are planning to acquire a company which is an expert in sample preparation to deal with that problem.

Based on our research, we define our strategic products as;

- HIV Chip;

- Avian Flu Detection Chip (Flu Chip);

- Cancer Screening/ Cancer Marker Chip.

Meanwhile, some other institutions and companies are also trying to come up with those products or improve the existing ones. 


\section{HIV chip}

More than 35 million people in developing countries are living with HIV infection. An enormous global effort is now underway to bring antiretroviral treatment to at least 3 million of those infected. While drug prices have dropped considerably, the cost and technical complexity of laboratory tests essential for the management of HIV disease, such as CD4 cell counts, remain prohibitive. New, simple, and affordable methods for measuring CD4 cells that can be implemented in resource-scarce settings are urgently needed.

McDevitt Research Laboratory, developed a prototype for a simple, rapid, and affordable method for counting CD4 lymphocytes. Microliter volumes of blood without further sample preparation are stained with fluorescent antibodies, captured on a membrane within a miniaturized flow cell and imaged through microscope optics with the type of charge-coupled device developed for digital camera technology. An associated computer algorithm converts the raw digital image into absolute CD4 counts and CD4 percentages in real time. The accuracy of this prototype system was validated through testing in the United States and Botswana, and showed close agreement with standard flow cytometry $(r=0.95)$ over a range of absolute CD4 counts, and the ability to discriminate clinically relevant CD4 count thresholds with high sensitivity and specificity [35].

\section{Avian flu detection chip (flu chip)}

Avian influenza viruses, known to cause avian flu, are of Type A influenza viruses that infect birds. There are 15 known $\mathrm{H}$ subtypes. While all subtypes can be found in birds, the highly pathogenic isolates of avian influenza viruses are of subtypes $\mathrm{H} 5$ and $\mathrm{H} 7$. Avian influenza is a viral disease that is spreading through bird populations across Asia, Africa, and Europe. The disease is of great concern because if the virus develops the capacity for human-to-human transmission, it could spread quickly around the globe.

Avian influenza viruses may be transmitted to humans mainly in two ways, either directly from birds or from avian virus-contaminated environments, or indirectly through an intermediate host, such as a pig.

Using the In-Check platform from STMicroelectronics, Veredus is trying to identify whether a patient is infected with Avian Flu (h5n1) or a subtype of Influenza A or B in a single test, rather than the multiple tests currently in use. The diagnostic chip is planned to handle 5 ? $\mu \mathrm{l}$ of blood; operate 25 to 30 thermal cycles over 20 minutes. The test is expected to cost between $\$ 20$ and \$25 [36], [37].

The Flu Chip is coated with 55 short stretches of RNA selected from 5,000 samples of human, bird, pig and horse flus provided by the CDC, and including $\mathrm{H} 5 \mathrm{~N} 1$ and routine human flus of the H3N2 and H1N1 strains. The broken-up DNA in the amplified sample is, in effect, poured across the chip, and fragments stick to the matching bits of RNA. By noting the matches, scientists can deduce which flu it is [38]. 


\section{Cancer Screening Chip/Cancer Marker Chip}

There are many type of Cancer, based on our research and survey we decide to propose these two products first. They are Lab-on-a-Chip for Breast Cancer Screening and Cervical Cancer Screening Chip. The detail of each Chip is stated below.

\section{Lab-on-a-chip for breast cancer screening}

Researchers at the Virginia Bioinformatics Institute (VBI) at Virginia Tech have developed a disposable microchip that replaces space-consuming instrumentation with fast, cost-effective, lab-on-a-chip technology. The microfluidic device is suitable for large-scale screening of diseaserelated biomarkers. Protein biomarkers are useful as "molecular indicators" for a wide range of diseases including breast cancer. The lab-on-a-chip integrates a pump, valve, separation column, and detection interface onto a 3- by-1 inch glass microchip and delivers a performance to match benchtop instrumentation typically occupying a few square feet of lab space.

The system combines liquid chromatographic separation of proteins driven by hundreds of parallel micro- and nanochannels. These channels, which have dimensions in the micrometer domain, serve to generate an electroosmotic flow. This flow of liquid helps to separate the proteins which are then identified by state-of-the-art mass spectrometric detection instruments. Researchers used the microchip to detect cancer biomarkers in cellular extracts generated from the MCF7 breast cancer cell line. 77 proteins were identified with confidence, five of which are known to be cancer-specific biomarkers [39].

\section{Cervical cancer screening chip}

Daiichi Pure Chemicals Co. Ltd, Toshiba Corporation, and Toshiba Hokuto Electronics Corporation have agreed to work together to promote in-vitro DNA-chip-based diagnostics, starting with diagnosis of the human papilloma virus (HPV). Infection with human papilloma virus (HPV) is the main cause of cervical cancer, the second most common cancer in women. Of its many strains 13 are potentially carcinogenic, but the cancer that they trigger can be treated and completely cured if detected at an early stage. Daiichi Pure Chemicals, Toshiba and Toshiba Hokuto Electronics aim to develop Japan's first in-vitro diagnostic system for HPV based on an electrochemical DNA detection chip [40].

Following to the Market analysis we got the list of potential market driver, and we also got the key strategic product feature by doing the Product analysis. To find the linkage between Market and Product layer, Analysis Grid is used. By using the Impact analysis between Market Drier and Product Feature, Experts scaled the impact of each key product feature vs. market driver as is shown in table 1. 


\begin{tabular}{|c|c|c|c|c|c|}
\hline \multirow[b]{2}{*}{ Product Feature } & \multicolumn{5}{|c|}{ Market Driver } \\
\hline & $\begin{array}{l}\text { Global Market } \\
\text { Needs } \\
\text { e.g. HIV, Avian } \\
\text { flu pandemic }\end{array}$ & $\begin{array}{c}\text { Health } \\
\text { Awareness }\end{array}$ & $\begin{array}{c}\text { Aging } \\
\text { Population }\end{array}$ & $\begin{array}{l}\text { Cost of } \\
\text { Healthcare }\end{array}$ & $\begin{array}{l}\text { Miniaturized } \\
\text { New Trend }\end{array}$ \\
\hline 1. Analysis time & $\mathbf{H}$ & $\mathbf{H}$ & $\mathbf{M}$ & $\mathbf{H}$ & $\mathbf{M}$ \\
\hline 2. Sample volume & $\mathbf{M}$ & $\mathbf{L}$ & $\mathbf{L}$ & $\mathbf{H}$ & $\mathbf{H}$ \\
\hline 3. Analysis cost & $\mathbf{H}$ & $\mathbf{H}$ & $\mathbf{H}$ & $\mathbf{H}$ & $\mathbf{L}$ \\
\hline 4. Portable size & H & $\mathbf{M}$ & $\mathbf{M}$ & $\mathbf{M}$ & $\mathbf{H}$ \\
\hline 5. Easy to use & H & $\mathbf{H}$ & $\mathbf{H}$ & $\mathbf{L}$ & $\mathbf{L}$ \\
\hline $\begin{array}{l}\text { 6. No. of detected } \\
\text { Diseases }\end{array}$ & $\mathbf{L}$ & $\mathbf{M}$ & $\mathbf{H}$ & $\mathbf{H}$ & $\mathbf{M}$ \\
\hline Strategic Product & HIV, Avian Flu & HIV\& Cancer & Cancer & $\begin{array}{l}\text { Every } \\
\text { Product }\end{array}$ & $\begin{array}{c}\text { Hybrid HIV, } \\
\text { Multiple } \\
\text { Cancer }\end{array}$ \\
\hline
\end{tabular}

Table 1 - Product feature vs. market driver matrix

\section{Technology analysis}

\section{Technology solution}

After identifying the main "Strategic Product" of Lab-on-a-Chip (LOC) e.g. HIV Chip, Avian Flu Detection Chip, and Cancer Screening Chip and Strategic Product Features already, the next step is to find Technology Solution by specifying the major technology areas and time line. LOC is a device that integrates multifunctional laboratory in a single chip. LOC devices are a subset of various technologies e.g. MEMS, Microfluidics, etc. For the LOC product of XI Company, the list of Technology areas and their time line can be listed in table 2 below.

\begin{tabular}{|c|c|c|c|}
\hline No. & Technology Solution & Time line (year) & Current Status \\
\hline 1 & Microfabrication & Current & $\begin{array}{c}\text { Mature Technology and } \\
\text { ready to use }\end{array}$ \\
\hline 2 & Microelectromechanical Systems (MEMS) & Current & $\begin{array}{c}\text { Mature Technology and } \\
\text { ready to use }\end{array}$ \\
\hline 3 & Microfluidics & $>1 \mathrm{y}$ & R\&D \\
\hline 4 & DNA Technology & $>2 \mathrm{y}$ & R\&D \\
\hline 5 & Biosensor & $>5 \mathrm{y}$ & $>8 \mathrm{y}$ \\
\hline 6 & Sample Preparation & $\begin{array}{c}\text { To be acquire from other } \\
\text { partners }\end{array}$ \\
\hline
\end{tabular}

Table 2 - Technology solution for lab-on-a-chip 
These technology solutions can help to meet the critical features of LOC strategic Products e.g. Speed up analysis times, Reduce sample volume, Reduce costs, and etc.

\section{Technology tree}

Once there is a list of technology solutions, the Technology Alternative that can help to meet the performance target must be identified. A difficult product might require breakthrough in various technologies or one technology might impact more than one product. When multiple technologies are being pursued at the same time, the decision will have to make for which technology will be selected or dropped for further consideration. In our case, the information is acquired from Expert Panel by using Delphi method to come up with the list of the LOC subtechnologies. Here is the list of LOC Technology Tree that shows Technology Areas and Technology Alternatives in each as well as the relationship to product features

\begin{tabular}{|c|c|c|c|c|c|c|}
\hline \multirow[b]{2}{*}{ Technology Alternative } & \multicolumn{6}{|c|}{ Product Feature } \\
\hline & $\begin{array}{l}\text { Analysis } \\
\text { times }\end{array}$ & $\begin{array}{l}\text { Sample } \\
\text { volume }\end{array}$ & $\begin{array}{l}\text { Analysis } \\
\text { cost }\end{array}$ & $\begin{array}{l}\text { Portable } \\
\text { Size }\end{array}$ & $\begin{array}{l}\text { Easy to } \\
\text { use }\end{array}$ & $\begin{array}{c}\text { No. of } \\
\text { Detected } \\
\text { Disease } \\
\end{array}$ \\
\hline \multicolumn{7}{|l|}{ 1. Microfabrication } \\
\hline $\begin{array}{l}\text { Non-Silicon/Silicon } \\
\text { Micromachining }\end{array}$ & $\mathbf{L}$ & $\mathbf{M}$ & $\mathbf{H}$ & $\mathbf{H}$ & $\mathbf{M}$ & $\mathbf{M}$ \\
\hline Micro Molding & $\mathbf{L}$ & $\mathbf{M}$ & $\mathbf{H}$ & $\mathbf{H}$ & $\mathbf{M}$ & $\mathbf{M}$ \\
\hline Contact Printing & $\mathbf{L}$ & $\mathbf{M}$ & $\mathbf{H}$ & $\mathbf{H}$ & $\mathbf{M}$ & $\mathbf{M}$ \\
\hline Nano-imprint & $\mathbf{L}$ & $\mathbf{M}$ & $\mathbf{H}$ & $\mathbf{H}$ & $\mathbf{M}$ & $\mathbf{M}$ \\
\hline Plastic micromolding & $\mathbf{L}$ & $\mathbf{M}$ & $\mathbf{M}$ & $\mathbf{M}$ & $\mathbf{L}$ & $\mathbf{L}$ \\
\hline Deep UV Photoresist & $\mathbf{L}$ & $\mathbf{M}$ & $\mathbf{M}$ & $\mathbf{M}$ & $\mathbf{L}$ & $\mathbf{L}$ \\
\hline Deep RIE (Dry etching) & $\mathbf{L}$ & $\mathbf{M}$ & $\mathbf{M}$ & $\mathbf{M}$ & $\mathbf{L}$ & $\mathbf{L}$ \\
\hline Focused Ion Beam Milling & $\mathbf{L}$ & $\mathbf{M}$ & $\mathbf{M}$ & $\mathbf{M}$ & $\mathbf{L}$ & \\
\hline \multicolumn{7}{|l|}{ 2. MEMS } \\
\hline Micro pump & $\mathbf{M}$ & $\mathbf{M}$ & $\mathbf{H}$ & $\mathbf{H}$ & $\mathbf{M}$ & $\mathbf{M}$ \\
\hline Micro vaule & $\mathbf{M}$ & $\mathbf{M}$ & $\mathbf{H}$ & $\mathbf{H}$ & $\mathbf{M}$ & $\mathbf{M}$ \\
\hline Micro needle & $\mathbf{M}$ & $\mathbf{M}$ & $\mathbf{H}$ & $\mathbf{H}$ & $\mathbf{M}$ & $\mathbf{M}$ \\
\hline MEMS packaging & $\mathbf{M}$ & $\mathbf{M}$ & $\mathbf{H}$ & $\mathbf{H}$ & $\mathbf{M}$ & $\mathbf{M}$ \\
\hline \multicolumn{7}{|l|}{ 3. Microfluidics } \\
\hline Mixing pre-concentration & $\mathbf{H}$ & $\mathbf{H}$ & $\mathbf{M}$ & $\mathbf{H}$ & $\mathbf{M}$ & $\mathbf{H}$ \\
\hline Electrokinetic Control & $\mathbf{H}$ & $\mathbf{H}$ & $\mathbf{M}$ & $\mathbf{H}$ & $\mathbf{M}$ & $\mathrm{H}$ \\
\hline Electroosmosis Flow Control & $\mathbf{H}$ & $\mathbf{H}$ & $\mathbf{M}$ & $\mathrm{H}$ & $\mathbf{M}$ & $\mathrm{H}$ \\
\hline Surface Acoustic Waves & $\mathbf{L}$ & $\mathbf{L}$ & $\mathbf{L}$ & $\mathbf{M}$ & $\mathbf{L}$ & $\mathbf{M}$ \\
\hline Dielectrophoresis (DEP) & L & $\mathrm{L}$ & $\mathbf{L}$ & $\mathbf{M}$ & $\mathbf{L}$ & $\mathbf{M}$ \\
\hline $\begin{array}{l}\text { Electrowetting-on dielectric } \\
\text { droplet (EWOD) }\end{array}$ & $\mathbf{L}$ & $\mathbf{L}$ & $\mathbf{L}$ & $\mathbf{M}$ & $\mathbf{L}$ & $\mathbf{M}$ \\
\hline \multicolumn{7}{|l|}{ 4. Biosensor } \\
\hline Fluorescence & $\mathbf{H}$ & $\mathbf{L}$ & $\mathbf{L}$ & $\mathbf{M}$ & $\mathbf{H}$ & $\mathbf{M}$ \\
\hline Surface Plasmon Resonance & $\mathbf{H}$ & $\mathbf{L}$ & $\mathbf{L}$ & $\mathbf{M}$ & $\mathbf{H}$ & $\mathbf{M}$ \\
\hline Piezoimmuno sensors & $\mathbf{H}$ & $\mathbf{L}$ & $\mathbf{L}$ & $\mathbf{M}$ & $\mathbf{H}$ & $M$ \\
\hline Wireless electrochemilumine & $\mathbf{M}$ & $\mathbf{L}$ & $\mathbf{L}$ & $\mathbf{L}$ & $\mathbf{M}$ & $\mathbf{L}$ \\
\hline Hydrogel & $\mathbf{M}$ & $\mathbf{L}$ & $\mathbf{L}$ & $\mathbf{L}$ & $\mathbf{M}$ & $\mathbf{L}$ \\
\hline Acoustic Biomedical Sensors & $\mathbf{M}$ & $\mathbf{L}$ & $\mathbf{L}$ & $\mathbf{L}$ & $\mathbf{M}$ & $\mathbf{L}$ \\
\hline Entrinsic Sensors & $M$ & $\mathbf{L}$ & $\mathbf{L}$ & $\mathbf{L}$ & $\mathbf{M}$ & $\mathbf{L}$ \\
\hline Optical Biomedical Sensors & $\mathbf{M}$ & $\mathbf{L}$ & $\mathbf{L}$ & $\mathbf{L}$ & $\mathbf{M}$ & $\mathbf{L}$ \\
\hline \multicolumn{7}{|l|}{ 5. DNA Technology: } \\
\hline DNA Extraction & $\mathbf{M}$ & $\mathbf{L}$ & $\mathbf{L}$ & $\mathbf{L}$ & $\mathbf{H}$ & $\mathbf{H}$ \\
\hline DNA amplification & $\mathbf{M}$ & $\mathbf{L}$ & $\mathbf{L}$ & $\mathbf{L}$ & $\mathbf{H}$ & $\mathbf{H}$ \\
\hline DNA hybridization & $\mathbf{M}$ & $\mathbf{L}$ & $\mathbf{L}$ & $\mathbf{L}$ & $\mathbf{H}$ & $\mathbf{H}$ \\
\hline $\begin{array}{l}\text { Single nucleotide } \\
\text { polymorphism (SNP) }\end{array}$ & $\mathbf{M}$ & $\mathbf{L}$ & $\mathbf{L}$ & $\mathbf{L}$ & $\mathbf{H}$ & $\mathbf{H}$ \\
\hline \multicolumn{7}{|l|}{ 6. Sample Preparation: } \\
\hline Sonication & $\mathbf{M}$ & $\mathbf{H}$ & $\mathbf{M}$ & $\mathrm{H}$ & $\mathbf{H}$ & $M$ \\
\hline Extraction & $\mathbf{M}$ & $\mathbf{H}$ & $\mathbf{M}$ & $\mathrm{H}$ & $\mathbf{H}$ & $M$ \\
\hline Preconcentration & $M$ & $\mathbf{H}$ & $\mathbf{M}$ & $\mathbf{H}$ & $\mathbf{H}$ & $\mathbf{M}$ \\
\hline
\end{tabular}

Table 3 - Impact of related technology with product feature of lab-on-a-chip Remark: Use "L"for low, "M"for medium, and " $\mathrm{H}$ "for high impact 


\section{Roadmapping}

Roadmapping is a process to integrate and link all of the important information of Market, Product and Technology [41]. According to the result from the first three analyses, Market Analysis, Product Analysis and Technology Analysis, and the result of the Analysis grid, Impact analysis of Market Driver and Product Feature, Impact analysis of Product Feature and Technology Alternative, enable to develop a simple framework of the three levels of the roadmap and also the linkage between each layer [42]. To draw the Marketing and Technology stands together to create the first roadmap. Normally, there are many types and formats of Roadmap [41]. The format of the TRM must be defined in terms of time scales and strategic factor levels e.g. market, product, technology, resource, regulation \& policy, etc. The key flagship and timeline, the product evolution, and the technological programs must be identified as well. Finally they will draw together with the linkages between each roadmap levels. And the most significant things to consider are the prioritized Market driver, the high impact Product feature and the most attractive technological solutions [43]. The product-technology roadmap is illustrated in figure 1.

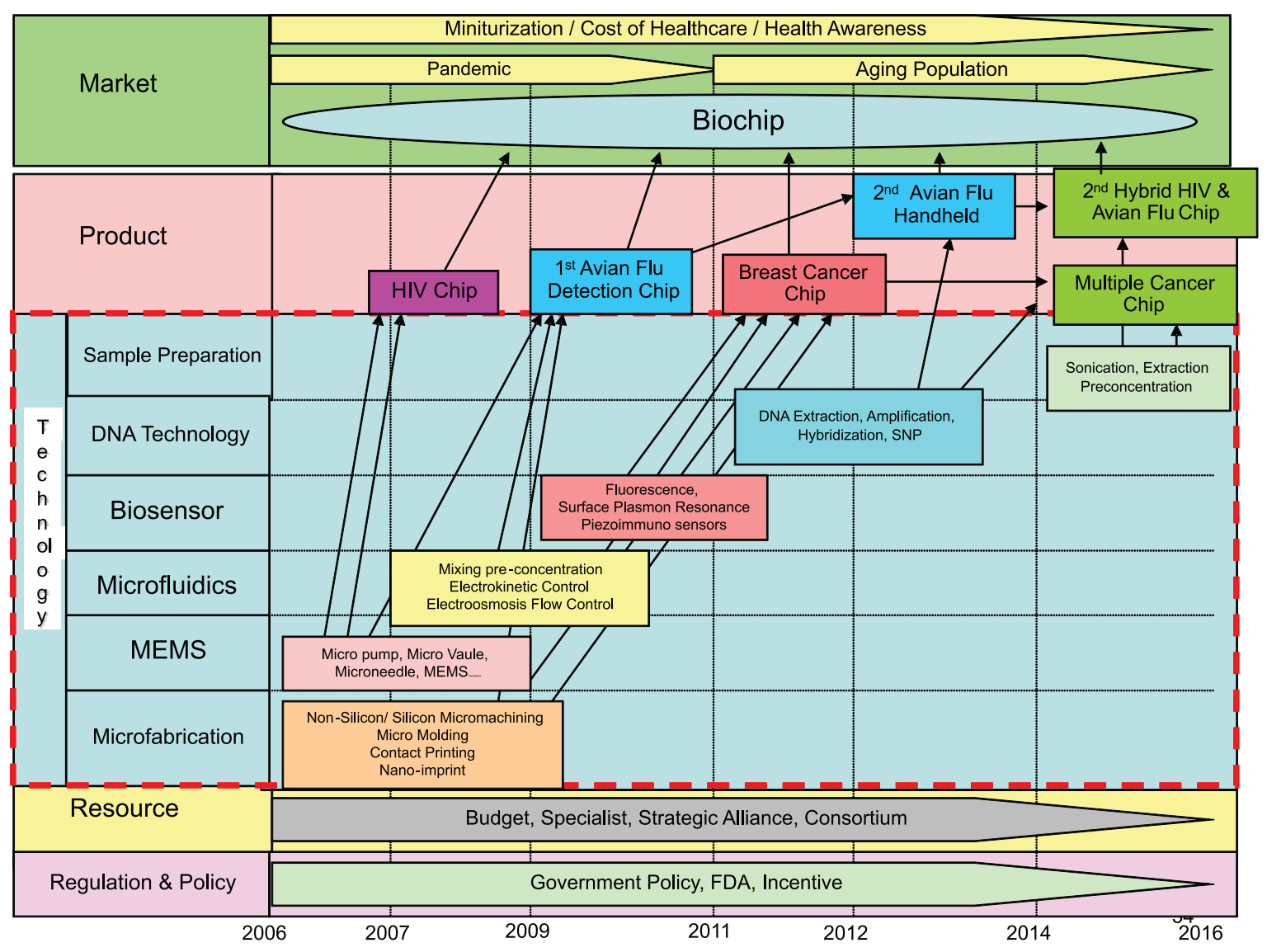

Figure 1 - Lab-on-a-chip product - technology roadmap 


\section{References}

[1] Yole Development Magazine Editors, "Biochips, what could be the factors impacting their success in routine testing," Micronews, pp 4-6, Aug-Sept. 2005.

[2] F. Su, K. Chakrabarty, and R.B. Fair, "Microfluidic-Based Biochips: Technology Issues, Implementation Platforms, and Design-Automation Challenges," IEEE Transactions on Computer-Aided Design of Integrated Circuits and Systems, vol. 25, no. 2, Feb. 2006.

[3] Wikipedia, "Biochip," no date specified. http://en.wikipedia.org/wiki/Biochip.

[4] Wikipedia, "Lab-on-a-chip," no date specified. http://en.wikipedia.org/wiki/Lab-on-a-chip.

[5] McDevitt Research Laboratory, University of Texas at Austin, "Lab-on-a-Chip Integration Theme: The Great Challenge," http://www.tastechip.com/labchip/lab_on_a_chip.html

[6] R. Phaal, C.J.P. Farrukh, and D.R. Probert, "Technology Roadmapping - A planning framework for evolution and revolution," Technological Forecasting and Social Change, 71: pp. 5-26, 2004.

[7] R. Phaal, C.J.P. Farrukh, and D.R. Probert, "Developing a Technology Roadmapping System," PICMET, Portland, 2005.

[8] R. J. Best, "Market-Based Management: Strategies for Growing Customer Value and Profitability," PrenticeHall Fourth Edition, P199

[9] www.americancentury.com/servlet/GlossaryManager/acb.americancentury.com/ilMMa.htm

[10] www.turnerlearning.com/efts/bball/econglos.htm

[11] Barriers to the commercialization issues of nanotechnology,

http://www.rgrace.com/Papers/Euro_Micro_Nano_b.html

[12] http://www.researchandmarkets.com/reports/c21981

[13] Biosensor Market, R\&D and Commercial Implication, http://www.fuji-keizai.com/e/report/biosensor2004_e.html

[14] The Yole Report

[ 15 ] h t t p://www.piribo.com/publications/it_e he alth/ bio_digital_europe_market_status_trends_future_outlook_2000_2010.html

[16] http://www.nanotechwire.com/news.asp?nid=1954\&ntid=126\&pg=8

[17] http://www.who.int/csr/disease/influenza/pandemic10things/en/index.html

[18]http://www.house.gov/list/speech/tx30_johnson/morenews/GlobalHIVAIDSPandemic.html

[19] http://www.newratings.com/analyst_news/article_1181519.html

[20] http://www.aoa.gov/prof/Statistics/statistics.asp

[21] http://www.yomiuri.co.jp/dy/features/0004/08.htm

Rev. Adm. UFSM, Santa Maria, v. 3, n.1, p. 160-173, jan./abr. 2010 
[22] http://www.yomiuri.co.jp/dy/national/20050609TDY04002.htm

[23] http://www.netmba.com/marketing/market/analysis/

[24] http://www.markets.duke.edu/student_it/mms190_fall2001_webteams/team3/barriers.html

[25] http://www.coursework4you.co.uk/porter.htm

[26] http://www.quickmba.com/strategy/porter.shtml

[27]http://www.markets.duke.edu/student_it/mms190_fall2001_webteams/team3/supplier.html

[28]http://www.markets.duke.edu/student_it/mms190_fall2001_webteams/team3/substitutes.html

[29] http://www.markets.duke.edu/student_it/mms190_fall2001_webteams/team3/rivalry.html

[30] http://www.st.com/stonline/stappl/press/news/year2006/t1753.htm

[31] K. W. Chan, M. Renee, "Blue Ocean Strategy," Harvard Business Review, vol. 82 Issue 10, p76-84, 9p, 2 charts, 1 diagram, October 2004.

[32] 12 manage.com, "Product/Market Grid (Ansoff)," March 2006, http://www.12manage.com/methods_productmarketgrid.html.

[33] http://www.market-modelling.co.uk/MATRIX/MATRIX_Step02_2.htm

[34] Tutor2u, "Ansoff Product/Market Analysis," 2005, http://www.tutor2u.net/business/strategy/ ansoff_matrix.htm.

[35]: http://www.tastechip.com/hiv/hiv_diagnostics.html

[36]: http://www.mtbeurope.info/news/2006/606008.htm

[37]: http://www.suframa.gov.br/minapim/news/visArtigo.cfm?ldent=213\&Lang=EN

[38]: http://www.tbo.com/news/scitech/MGBESZE3KRE.html

[39]: http://www.azonano.com/news.asp?newsID =2959

[40]: http://www.toshiba.co.jp/about/press/2006_07/pr1101.htm

[41] David Probert and Noordin Shehabuddeen Technology road mapping: the issues of managing technology change, Volume 17, Number 6/1999

[42] R. Phaal, C. J. P. Farrukh, and D. R. Probert, "Technology roadmapping - A planning framework for evolution and revolution," Technological Forecasting and Social Change, pp. 5-26, May 2003.

[43] R Phaal, CJP Farrukh and DR Probert, "Fast Start Technology Roadmapping”, 9th International Conference on the Management of Technology (IAMOT 2000), February 2000, Miami.

[44] David Probert, "Linking technology to future markets: development and application of technology roadmapping," Horizon R\&D Management Seminar, 17 March 2004. 